\title{
The Bidirectional Relationship Between Debts and Common Mental Disorders: Results of a longitudinal Population-Based Study
}

\author{
Margreet Ten Have $^{1}$ (D) Marlous Tuithof ${ }^{1} \cdot$ Saskia Van Dorsselaer ${ }^{1} \cdot$ Derek De Beurs $^{1,2} \cdot$ Bertus Jeronimus $^{3}$. \\ Peter De Jonge ${ }^{3} \cdot$ Ron De Graaf ${ }^{1}$
}

Accepted: 22 March 2021 / Published online: 13 April 2021

(c) The Author(s), under exclusive licence to Springer Science+Business Media, LLC, part of Springer Nature 2021

\begin{abstract}
Researchers and politicians have regularly expressed their worries about a widening of socioeconomic inequalities in physical and mental health. Debts have been relatively understudied as a specific aspect of socioeconomic disadvantage contributing to poor mental health. This study examines the bidirectional association between debts and common mental disorders (CMDs) in the adult population of the Netherlands. Data were obtained from the second ('baseline') and third (3-year follow-up) wave of the Netherlands Mental Health Survey and Incidence Study-2, a representative cohort of adults. Questions were asked about debts and difficulty in repaying debts in the past 12 months. The answers were combined into one variable: no debts, easy, difficult, and very difficult to pay back debts. Twelve-month CMDs were assessed with the Composite International Diagnostic Interview version 3.0. Increasing levels of difficulty in repaying debts predicted onset of CMD at follow-up in those without 12-month CMD at baseline, and persistence of CMD at follow-up in those with 12-month CMD at baseline. Conversely, CMD was not linked to onset of debts at follow-up in those without 12-month debts at baseline, but was associated with persistence of difficulty to pay back debts at follow-up in those with 12-month debts at baseline. These associations remained significant after adjustment for baseline sociodemographic variables, negative life events and physical health. Health professionals and debt counsellors should pay more attention to patients' debts and clients' mental health respectively in order to refer those with financial or mental health problems to the appropriate services.
\end{abstract}

Keywords Debts $\cdot$ Common mental disorder $\cdot$ Population survey $\cdot$ Prospective cohort study

$\begin{array}{ll}\text { Abbreviations } \\ \text { CIDI } & \begin{array}{l}\text { Composite international diagnostic } \\ \text { interview } \\ \text { Diagnostic and statistical manual of mental } \\ \text { disorders }\end{array} \\ \text { METIGG } & \begin{array}{l}\text { Medical Ethics Review Committee for } \\ \text { Institutions on Mental Health Care } \\ \text { NEMESIS-2 }\end{array} \\ & \begin{array}{l}\text { Netherlands Mental Health Survey and } \\ \text { Incidence Study-2 }\end{array} \\ \end{array}$

Margreet Ten Have

mhave@trimbos.nl

1 Netherlands Institute of Mental Health and Addiction, Da Costakade 45, 3521 VS Utrecht, The Netherlands

2 Department of Clinical, Neuro and Developmental Psychology, Vrije Universiteit Amsterdam, Amsterdam, The Netherlands

3 Department of Developmental Psychology, Behavioral and Social Sciences, University of Groningen, Groningen, The Netherlands

$\begin{array}{ll}\text { STATA } & \begin{array}{l}\text { A general-purpose statistical software } \\ \text { package created in } 1985 \text { by StataCorp }\end{array} \\ \mathrm{T}_{0} & \text { First wave } \\ \mathrm{T}_{1} & \text { First follow-up wave } \\ \mathrm{T}_{2} & \text { Second follow-up wave }\end{array}$

\section{Introduction}

Over the past decades researchers and politicians have regularly expressed their worries about a widening of socioeconomic inequalities in health (e.g., The Black Report, 1980; Matthews and Gallo, 2011) and public health policies emerged to reverse this process (Dubois et al., 2020; Piketty, 2014). In Europe between 14 and 21\% of the citizens grapple with difficulties in repaying debts (Dubois et al., 2020; Den Ridder et al., 2020); a figure that probably will rise in the near future. Debts have been relatively understudied and acknowledged as a specific aspect of socioeconomic disadvantage contributing to poor mental health (Arber et al., 
2014; Fitch et al., 2011; Gunasinghe et al., 2018; Jenkins et al., 2008; Richardson et al., 2013; Sweet et al., 2013).

Despite the different definitions used to assess debts, the picture arising from the studies thus far is rather consistent. Debt was cross-sectionally associated with depressive or anxiety symptoms (Dackehag et al., 2018; Drentea \& Reynolds, 2012; Hintikka et al., 1998; Sweet et al., 2013; Zimmerman \& Katon, 2005; Zurlo et al., 2014), common mental disorders (CMDs, i.e. mood, anxiety and substance use disorders; (Jenkins et al., 2008; Meltzer et al., 2012) and suicidal ideation (Meltzer et al., 2011). Furthermore, the more debts people had, the more likely they were to have some form of CMD (Jenkins et al., 2008) or suicidal ideation (Meltzer et al., 2011).

The evidence from the existing studies on the association between debts and mental health (see Appendix) is hampered in at least four major ways: (1) evidence is predominantly cross-sectional (Hojman et al., 2016); (2) most studies were performed in the years surrounding the 2008 financial crisis, (3) were predominantly conducted in England and the United States, and (4) assessed depressive or anxiety symptoms instead of diagnoses of CMDs (Richardson et al., 2013). Consequently, we lack insight into whether having debts precedes onset or poor prognosis of someone's mental health, and vice versa, whether poor mental health results in onset or persistence of debts; a bidirectionality that requires longitudinal evidence.

The available longitudinal and population-based studies found that debt increased the risk of depressive symptoms (Hojman et al., 2016) and CMD (Gunasinghe et al., 2018). Less studied is the effect of having debts on the persistence of already existing mental health problems. Furthermore, research on the effect of poor mental health on onset and persistence of debts is lacking, apart from a study that found a link running from mental ill health to later payment difficulties (Dackehag et al., 2018).

The present study expands previous research by examining the bidirectional longitudinal association between debts and CMD in the adult population of the Netherlands, the knowledge generated may provide useful information to prevent onset and persistence of debts and poor mental health. Data were used from the Netherlands Mental Health Survey and Incidence Study-2 (NEMESIS-2), a nationally representative cohort of adults. A standardized diagnostic instrument was used to assess DSM (Diagnostic and Statistical Manual of Mental Disorders)-IV diagnoses.

\section{Methods}

NEMESIS-2 is a psychiatric epidemiological cohort study of the Dutch general population aged 18-64 years. It is based on a multistage, stratified random sampling of households, with one respondent randomly selected in each household. Based on the most recent birthday at first contact within the household, an individual aged 18-64 years with sufficient fluency in the Dutch language was randomly selected. Addresses of institutions and thus institutionalized individuals (i.e. those living in hospices, prisons) were excluded. Those temporarily living in institutions, however, could be interviewed later during the fieldwork if they returned home.

In the first wave $\left(\mathrm{T}_{0}\right)$, performed from November 2007 to July 2009, a total of 6,646 persons were interviewed (response rate 65.1\%; average interview duration: $95 \mathrm{~min}$ ). This sample was nationally representative, although younger subjects were somewhat underrepresented (De Graaf et al., 2010). The interviews were laptop computer-assisted and almost all were held at the respondent's home. All $\mathrm{T}_{0}$ respondents were approached for follow-up, three years after $\mathrm{T}_{0}$. Of this group, 5303 persons could be interviewed again (response rate $80.4 \%$, with those deceased excluded; average interview duration: $84 \mathrm{~min}$ ). All $\mathrm{T}_{1}$ respondents were approached for second follow-up $\left(\mathrm{T}_{2}\right)$, another three years later; 4,618 persons were re-interviewed (response rate $87.8 \%$; duration: $83 \mathrm{~min}$ ). Attrition rate over the six years between $T_{0}$ and $T_{2}$ was not significantly associated with all main categories and individual 12-month mental disorders at baseline, after controlling for sociodemographic characteristics, except for bipolar disorder (De Graaf et al., 2015). Attrition at $T_{2}$ was also not significantly associated with having debts at $\mathrm{T}_{1}$.

For this paper, data from the second and third wave were used, when data on debts and CMD were collected. The study was approved by a medical ethics committee (the Medical Ethics Review Committee for Institutions on Mental Health Care, METIGG). After having been informed about the study aims, at each wave respondents provided written informed consent. A more comprehensive description of the design is provided in De Graaf et al. (2010).

\section{Measures}

\section{Debts and Difficulty Repaying Debts}

At both waves respondents were asked to indicate whether they had incurred debts or were behind in paying within the time allowed for the following items in the past 12 months: rent or mortgage repayments, utilities (gas, water, electricity rates), tax, different types of loan, credit card payments, mail-order payments. Being in debt or behind in any of these payments was regarded as having a debt. Those having a debt were also asked how much difficulty they had in paying off their debts (not difficult, difficult, very difficult). In most analyses both variables were combined into one variable with four answer categories: no debts, easy to pay back 
debts, difficult to pay back debts, and very difficult to pay back debts.

\section{Common Mental Disorders}

DSM-IV diagnoses of common mental disorders (CMDs) were made using the CIDI 3.0 - a fully structured layadministered diagnostic interview. This instrument was developed and adapted for use in the World Mental Health Survey Initiative (Kessler \& Üstün, 2004). The CIDI 3.0 version used in NEMESIS-2 was an improvement on the Dutch version used in the World Mental Health Survey Initiative.

The disorders assessed include: mood disorders (i.e. major depression, dysthymia, and bipolar disorder), anxiety disorders (i.e. panic disorder, agoraphobia without panic disorder, social phobia, specific phobia, and generalized anxiety disorder) and substance use disorders (i.e. alcohol/ drug abuse and dependence). Any CMD refers to any of these disorders. We assessed 12-month CMD, which means that somewhere in this 12-month prior to the interview the respondent has met criteria for a CMD. CMD differ in severity (Ten Have et al., 2013), and partly as a consequence not all people with a CMD seek professional help for their mental health problems or use psychotropic medication (Ten Have et al., 2013, 2018; Bosman et al., 2019).

Clinical calibration studies in various countries (Haro et al., 2006) found that the CIDI 3.0 assesses mood, anxiety and substance use disorders with generally good validity in comparison to blinded clinical reappraisal interviews.

\section{Potential Confounders}

Based on previous research (Hojman et al., 2016; Meltzer et al., 2012), a selection was made of variables related to debts and CMDs, all of which were assessed at $\mathrm{T}_{1}$, except for education (assessed at $\mathrm{T}_{0}$ ). Included sociodemographic variables were gender, age, education, living situation, and job status. The presence of ten common adult negative life events over the past 12 months were assessed with the Brugha List of Threatening Experiences (Brugha et al., 1985), e.g., death of a relative or friend and divorce. Our physical health variables included any chronic physical disorder, i.e. presence of $\geq 1$ of 17 chronic physical disorders treated or monitored by a medical doctor in the previous 12 months, assessed with a standard checklist; body mass index (BMI); and current smoking status.

\section{Statistical Analyses}

All analyses were performed with STATA version 12.1, using weighted data to correct for differences in the response rates in several sociodemographic groups at all waves and differences in the probability of selection of respondents within households at $\mathrm{T}_{0}$. Robust standard errors were calculated in order to obtain correct $95 \%$ confidence intervals and p-values (Skinner et al., 1989).

Based on presence/absence of a 12-month CMD and debt status at $\mathrm{T}_{1}$ (herein after referred to as 'baseline'), four sub-cohorts were established: (a) respondents without a 12-month CMD ( $\mathrm{n}=4110$ : 3705 without debts; 397 with debts); (b) respondents with a 12-month CMD ( $n=508$ : 386 without debts; 121 with debts); (c) respondents without debts $(n=4091$ : 3705 without CMD; 386 with CMD); and d) respondents with debts $(n=518: 397$ without CMD; 121 with CMD). Subsequently, after three years at $T_{2}$ (herein after referred to as 'follow-up'), the occurrence of the outcome variables of interest was calculated in each sub-cohort, being respectively: (a) onset and (b) persistence of 12-month CMD; and (c) onset and (d) persistence of difficulty in repaying debts. Next, separately for each sub-cohort, univariate analyses were performed to examine the associations of the predictor and potentially confounding variables with the outcome variable, followed by testing two multivariate models in which the effect of the predictor variable was adjusted for gender and age (model 1), and additionally for the other sociodemographic variables as well as any negative life event, any chronic physical disorder, BMI and current smoking status (model 2) (Tables 1, 2, 3 4).

Logistic regression analyses were used to examine whether difficulty in repaying debts at baseline (as compared to no debts) predicted onset and persistence of 12-month $\mathrm{CMD}$ at follow-up. Multinomial regression analyses were carried out to investigate whether 12-month CMD at baseline (as compared to no CMD) was a risk factor for onset and persistence of difficulty in repaying debts at follow-up.

To ensure representativeness, the data were weighted to correct for differences in the response rates in several sociodemographic groups at both waves and differences in the probability of selection of respondents within households at baseline.

Finally, as the structure of CMDs can be explained by two broad underlying domains, i.e. internalizing and externalizing disorders (Vollebergh et al, 2001), all analyses were also conducted separately for mood or anxiety disorder and substance use disorder (Supplementary Appendix 1-4).

\section{Results}

\section{Baseline Debts as a Predictor for Onset of CMD at Follow-Up}

Of the sub-cohort of respondents without a 12-month CMD at baseline, $10.9 \%$ had debts and $4.3 \%$ experienced difficulty in paying back their debts. At follow-up, $9.0 \%$ of this sub-cohort developed a 12-month CMD (not tabulated). 
Table 1 The association between debts at baseline and onset of common mental disorder (CMD) at follow-up

\begin{tabular}{|c|c|c|c|c|c|}
\hline & \multicolumn{2}{|c|}{ Total $(\mathrm{N}=4110)$} & \multicolumn{3}{|c|}{ 12-month CMD at follow-up } \\
\hline & & & & Model 1 & Model 2 \\
\hline Baseline characteristics & $\mathrm{n}$ & $\%$ or M (S.E.) & $\%$ or M (S.E.) & $\mathrm{aOR}(95 \% \mathrm{CI})$ & $\mathrm{aOR}(95 \% \mathrm{CI})$ \\
\hline \multicolumn{6}{|l|}{ Debts } \\
\hline No & 3705 & 89.1 & 82.1 & REF & REF \\
\hline Yes and easy to pay back & 249 & 6.6 & 9.3 & $1.42[0.86,2.35]$ & $1.26[0.76,2.09]$ \\
\hline Yes and difficult to pay back & 94 & 2.8 & 3.5 & $1.27[0.70,2.30]$ & $1.03[0.55,1.92]$ \\
\hline Yes and very difficult to pay back & 54 & 1.5 & 5.1 & $5.05[2.19,11.64]^{* * *}$ & $3.37[1.35,8.45]^{* *}$ \\
\hline$P$ for trend & & & & $\mathbf{0 . 0 0 2} * *$ & $0.042 *$ \\
\hline Female gender & 2240 & 49.0 & 55.9 & $1.34[0.99,1.80]+$ & $1.30[0.97,1.74]+$ \\
\hline Age at interview & 4110 & $45.6(0.37)$ & $42.1(1.04)$ & $0.98[0.97,0.99]^{* * *}$ & $0.97[0.96,0.99]^{* * *}$ \\
\hline \multicolumn{6}{|l|}{ Education } \\
\hline Primary education & 163 & 6.2 & 7.0 & & $0.98[0.49,1.96]$ \\
\hline Lower secondary & 1054 & 21.7 & 21.0 & & $0.84[0.52,1.36]$ \\
\hline Higher secondary & 1289 & 41.3 & 44.9 & & $1.05[0.74,1.50]$ \\
\hline Higher professional, university & 1604 & 30.8 & 27.1 & & REF \\
\hline Living without partner & 1080 & 26.5 & 39.2 & & $1.53[1.04,2.24]^{*}$ \\
\hline No paid job & 1075 & 23.7 & 26.3 & & $1.29[0.86,1.95]$ \\
\hline Any negative life event & 1808 & 43.5 & 50.1 & & $1.19[0.92,1.54]$ \\
\hline Any chronic physical disorder & 1706 & 38.9 & 44.1 & & $1.40[1.04,1.90]^{*}$ \\
\hline Body mass index & 4093 & $25.6(0.11)$ & $25.4(0.28)$ & & $1.01[0.98,1.04]$ \\
\hline Current smoking & 975 & 24.7 & 35.3 & & $1.73[1.23,2.43]^{* *}$ \\
\hline
\end{tabular}

Left part: Characteristics of respondents without a 12-month common mental disorder (CMD) at baseline, in total and across 12-month CMD status at follow-up three years later, in weighted column percentages or means (M) and standard errors (S.E.)

Right part: Results of logistic regression analyses predicting onset of 12-month CMD at follow-up (reference group is no CMD at follow-up), in weighted adjusted odds ratios (aOR) with $95 \%$ confidence intervals $(95 \% \mathrm{CI})$

REF: Reference category

Model 1 and Model 2: All odds ratios are adjusted for all variables in the column concerned

Bold: Significant OR at the 0.05 level, 2 -sided test. $+: P<.10 ; *: P<.05 ; * *: P<.01 ; * * *: P<.001$

Comparable analyses with internalizing (mood/anxiety) and externalizing (substance use) disorders separately are provided in supplementary Tables $1 \mathrm{a}, \mathrm{b}$ respectively

Univariate and multivariate logistic regression analyses showed that increasing levels of difficulty in repaying debts increased the risk of developing CMD at follow-up (see Table 1, $\mathrm{P}$ for trend at the right side). Those who experienced very much difficulty in repaying debts had a 3-5 times higher odds of developing a CMD at follow-up compared to those without debts at baseline. This effect did not hold for the other categories of debtors. Similar results were found for the associations between difficulty in repaying debts at baseline and onset of both types of CMD at follow-up (mood or anxiety disorder, and substance use disorder; see Supplementary Appendix 1).

\section{Baseline Debts as a Predictor of Persistent CMD at Follow-Up}

Thirty percent of the sub-cohort of respondents with a 12-month CMD at baseline reported debts and 17.9\% experienced difficulty in paying back their debts. At follow-up, $43.7 \%$ of this sub-cohort again had a 12 -month CMD (not tabulated). Univariate and multivariate logistic regression analyses showed that increasing levels of difficulty in repaying debts predicted persistence of CMD at follow-up (see Table 2, $\mathrm{P}$ for trend at the right side). Those who experienced very much difficulty in repaying debts had a 4-5 times higher odds of persistent CMD at follow-up compared to those without debts at baseline. This did not hold for the category of debtors who experienced less difficulty in repaying their debts. Similar results were found for the association between difficulty in repaying debts at baseline and persistence of substance use disorder at follow-up, but less so for persistence of mood or anxiety disorder at follow-up (Supplementary Appendix 2). 
Table 2 The association between debts at baseline and persistence of common mental disorder (CMD) at follow-up

\begin{tabular}{|c|c|c|c|c|c|}
\hline & \multicolumn{2}{|c|}{ Total $(\mathrm{N}=508)$} & \multicolumn{3}{|c|}{ 12-month CMD at follow-up } \\
\hline & & & & Model 1 & Model 2 \\
\hline Baseline characteristics & $\mathrm{n}$ & $\%$ or $\mathrm{M}(\mathrm{S} . \mathrm{E})$. & $\%$ or M (S.E.) & $\mathrm{aOR}(95 \% \mathrm{CI})$ & $\mathrm{aOR}(95 \% \mathrm{CI})$ \\
\hline \multicolumn{6}{|l|}{ Debts } \\
\hline No & 386 & 69.5 & 58.8 & REF & REF \\
\hline Yes and easy to pay back & 50 & 12.6 & 15.9 & $1.93[1.01,3.68]^{*}$ & $1.66[0.86,3.20]$ \\
\hline Yes and difficult to pay back & 34 & 9.7 & 11.0 & $1.66[0.57,4.86]$ & $1.36[0.44,4.23]$ \\
\hline Yes and very difficult to pay back & 37 & 8.2 & 14.3 & $5.25[2.04,13.51]^{* * *}$ & $4.10[1.49,11.29]^{* *}$ \\
\hline$P$ for trend & & & & $\mathbf{0 . 0 0 1} * * *$ & $0.020 *$ \\
\hline Female gender & 319 & 58.1 & 60.3 & $1.20[0.78,1.83]$ & $1.13[0.71,1.79]$ \\
\hline Age at interview & 508 & $39.5(0.72)$ & $37.7(1.14)$ & $0.98[0.97,1.00]+$ & $0.98[0.97,1.00]+$ \\
\hline \multicolumn{6}{|l|}{ Education } \\
\hline Primary education & 23 & 11.3 & 17.0 & & $1.68[0.58,4.84]$ \\
\hline Lower secondary & 139 & 25.7 & 24.7 & & $0.85[0.39,1.83]$ \\
\hline Higher secondary & 190 & 41.2 & 39.2 & & $1.06[0.55,2.02]$ \\
\hline Higher professional, university & 156 & 21.8 & 19.1 & & $\mathrm{REF}$ \\
\hline Living without partner & 227 & 48.4 & 60.6 & & $1.53[0.96,2.44]+$ \\
\hline No paid job & 167 & 28.6 & 37.6 & & $2.40[1.43,4.02]^{* * *}$ \\
\hline Any negative life event & 288 & 57.3 & 61.7 & & $1.07[0.70,1.64]$ \\
\hline Any chronic physical disorder & 247 & 43.0 & 41.2 & & $0.86[0.52,1.42]$ \\
\hline Body mass index & 504 & $25.6(0.34)$ & $25.1(0.39)$ & & $0.97[0.92,1.02]$ \\
\hline Current smoking & 196 & 42.7 & 47.5 & & $0.94[0.60,1.48]$ \\
\hline
\end{tabular}

Left part: Characteristics of respondents with a 12-month common mental disorder (CMD) at baseline, in total and across 12-month CMD status at follow-up three years later, in weighted column percentages or means (M) and standard errors (S.E.)

Right part: Results of logistic regression analyses predicting persistence of 12-month CMD at follow-up (reference group is no CMD at followup), in weighted adjusted odds ratios (aOR) with $95 \%$ confidence intervals (95\% CI)

REF: Reference category

Model 1 and Model 2: All odds ratios are adjusted for all variables in the column concerned

Bold: Significant OR at the 0.05 level, 2 -sided test. $+: P<.10 ; *: P<.05 ; * *: P<.01 ; * * *: P<.001$

Comparable analyses with internalizing (mood/anxiety) and externalizing (substance use) disorders separately are provided in supplementary Tables $2 \mathrm{a}, \mathrm{b}$ respectively

\section{Baseline CMD as a Predictor for Onset of Debts at Follow-Up}

Of the sub-cohort of respondents without debts at baseline, $10.9 \%$ had a 12 -month CMD. At 3-year follow-up, $8.2 \%$ of this sub-cohort developed debts; $4.7 \%$ reported the debts were easy to pay off, and $3.5 \%$ that they were (very) difficult to pay off (not tabulated). In univariate multinomial regression analysis CMD at baseline increased the risk of onset of easy and (very) difficult to pay off debts at follow-up (see Table 3, right side). In multivariate analysis CMD was no longer predictive of subsequent onset of difficulty in repaying debts. Stronger results were found for the association between mood or anxiety disorder at baseline and onset of debts at follow-up, but less for substance use disorder as a predictor of onset of debts at follow-up (Supplementary Appendix 3).

\section{Baseline CMD as a Predictor of Persistent Debts at Follow-Up}

Of the sub-cohort of respondents with debts at baseline, $30.4 \%$ had a 12 -month CMD. At follow-up, $53.7 \%$ of this sub-cohort again reported debts; $25.2 \%$ reported the debts were easy to pay off, and $28.5 \%$ that they were (very) difficult to pay off (not tabulated). Univariate and multivariate multinomial logistic regression analyses showed that CMD at baseline increased the likelihood of (very) difficult to pay off debts at follow-up (see right part of Table 4). Similar results were found for the association between mood or anxiety disorder at baseline and persistence of debts at follow-up, but not for substance use disorder as a predictor of persistent debts at follow-up (Supplementary Appendix 4). 
Table 3 The association between common mental disorder (CMD) at baseline and onset of debts at follow-up

\begin{tabular}{|c|c|c|c|c|c|c|c|c|}
\hline & \multicolumn{2}{|c|}{ Total $(\mathrm{N}=4091)$} & \multicolumn{6}{|c|}{ Debts at follow-up } \\
\hline & & & \multirow[b]{2}{*}{$\begin{array}{l}\text { Yes: easy to } \\
\text { pay back }\end{array}$} & \multirow[b]{2}{*}{$\begin{array}{l}\text { Yes: difficult } \\
\text { to pay back }\end{array}$} & \multicolumn{2}{|l|}{ Model 1} & \multicolumn{2}{|l|}{ Model 2} \\
\hline & & & & & $\begin{array}{l}\text { Yes easy to pay } \\
\text { back vs. no debts }\end{array}$ & $\begin{array}{l}\text { Yes difficult to } \\
\text { pay back vs. no } \\
\text { debts }{ }^{1}\end{array}$ & $\begin{array}{l}\text { Yes easy to pay } \\
\text { back vs. no debts }\end{array}$ & $\begin{array}{l}\text { Yes difficult to } \\
\text { pay back vs. no } \\
\text { debts }{ }^{1}\end{array}$ \\
\hline $\begin{array}{l}\text { Baseline char- } \\
\text { acteristics }\end{array}$ & $\mathrm{n}$ & $\%$ or M (S.E.) & $\%$ or M (S.E.) & $\%$ or M (S.E.) & aRRR (95\% CI) & aRRR (95\% CI) & aRRR (95\% CI) & aRRR (95\% CI) \\
\hline $\begin{array}{l}\text { 12-month } \\
\text { CMD }\end{array}$ & 386 & 10.9 & 21.2 & 23.3 & $2.01[1.02,3.94]^{*}$ & $\begin{array}{l}2.28 \\
{[1.35,3.84]^{* *}}\end{array}$ & $\begin{array}{l}1.85 \\
{[0.91,3.79]+}\end{array}$ & $1.52[0.92,2.53]$ \\
\hline $\begin{array}{l}\text { Female } \\
\text { gender }\end{array}$ & 2278 & 50.3 & 47.6 & 60.9 & $0.88[0.56,1.36]$ & $1.50[0.82,2.74]$ & $0.92[0.59,1.43]$ & $1.26[0.67,2.38]$ \\
\hline $\begin{array}{l}\text { Age at inter- } \\
\text { view }\end{array}$ & 4091 & $45.5(0.38)$ & $38.6(1.60)$ & $40.5(2.04)$ & $\begin{array}{l}0.96 \\
{[0.94,0.98]^{* * *}}\end{array}$ & $\begin{array}{l}0.97 \\
{[0.95,0.99]^{*}}\end{array}$ & $\begin{array}{l}0.96 \\
{[0.94,0.98]^{* * *}}\end{array}$ & $\begin{array}{l}0.95 \\
{[0.93,0.98]^{* *}}\end{array}$ \\
\hline \multicolumn{9}{|l|}{ Education } \\
\hline $\begin{array}{l}\text { Primary } \\
\text { education }\end{array}$ & 152 & 6.0 & 3.4 & 15.2 & & & $0.45[0.17,1.24]$ & $\begin{array}{l}3.71 \\
{[1.62,8.48]^{* *}}\end{array}$ \\
\hline $\begin{array}{l}\text { Lower sec- } \\
\text { ondary }\end{array}$ & 1056 & 21.9 & 24.5 & 26.7 & & & $0.72[0.41,1.25]$ & $1.65[0.81,3.36]$ \\
\hline $\begin{array}{l}\text { Higher sec- } \\
\text { ondary }\end{array}$ & 1294 & 41.4 & 34.2 & 44.4 & & & $0.55[0.34,0.90]^{*}$ & $1.79[1.02,3.14]^{*}$ \\
\hline $\begin{array}{l}\text { Higher pro- } \\
\text { fessional }\end{array}$ & 1589 & 30.7 & 37.9 & 13.8 & & & REF & REF \\
\hline $\begin{array}{l}\text { Living with- } \\
\text { out partner }\end{array}$ & 1074 & 26.2 & 39.0 & 38.9 & & & $1.52[0.89,2.61]$ & $1.26[0.69,2.29]$ \\
\hline No paid job & 1112 & 24.3 & 18.4 & 42.2 & & & $1.14[0.59,2.21]$ & $\begin{array}{l}2.88 \\
{[1.42,5.84]^{* *}}\end{array}$ \\
\hline $\begin{array}{l}\text { Negative life } \\
\text { event }\end{array}$ & 1806 & 43.3 & 49.1 & 54.8 & & & $1.24[0.80,1.91]$ & $1.39[0.81,2.40]$ \\
\hline $\begin{array}{l}\text { Chronic } \\
\text { physical } \\
\text { disorder }\end{array}$ & 1721 & 39.4 & 32.5 & 47.3 & & & $0.94[0.54,1.66]$ & $1.48[0.83,2.64]$ \\
\hline $\begin{array}{l}\text { Body mass } \\
\text { index }\end{array}$ & 4072 & $25.6(0.11)$ & $26.0(0.33)$ & $25.9(0.59)$ & & & $1.05[1.01,1.10]^{*}$ & $1.02[0.97,1.08]$ \\
\hline $\begin{array}{l}\text { Current smok- } \\
\text { ing }\end{array}$ & 967 & 24.6 & 28.4 & 45.5 & & & $1.20[0.76,1.87]$ & $\begin{array}{l}2.48 \\
{[1.56,3.94]^{* * * *}}\end{array}$ \\
\hline
\end{tabular}

Left part: Characteristics of respondents without debts at baseline, in total and across debts status at follow-up three years later, in weighted column percentages or means (M) and standard errors (S.E.)

Right part: Results of multinomial logistic regression analyses predicting onset of debts at follow-up (reference group is no debts at follow-up), in weighted adjusted relative risk ratios (aRRR) with 95\% confidence intervals (95\% CI)

1: The category difficult to pay back includes the categories difficult and very difficult to pay back debts

REF: Reference category

Model 1 and Model 2: All odds ratios are adjusted for all variables in the column concerned

Bold: Significant OR at the 0.05 level, 2 -sided test. $+: P<.10 ; *: P<.05 ; * *: P<.01 ; * * *: P<.001$

Comparable analyses with internalizing (mood/anxiety) and externalizing (substance use) disorders separately are provided in supplementary Table $3 \mathrm{a}$

\section{Discussion}

\section{Key Findings}

Most people with CMD do not have problematic debts, and most people with debts do not have CMD. However, increasing levels of difficulty in repaying debts among adults in a population-based study in the Netherlands predicted onset and persistence of CMD at follow-up. Conversely, CMD was not linked to onset of debts, but was associated with persistence of difficult to pay off debts at follow-up. These associations were robust and remained 
Table 4 The association between common mental disorder (CMD) at baseline and persistence of debts at follow-up

\begin{tabular}{|c|c|c|c|c|c|c|c|c|}
\hline & \multicolumn{2}{|c|}{ Total $(\mathrm{N}=518)$} & \multicolumn{6}{|c|}{ Debts at follow-up } \\
\hline & & & \multirow[b]{2}{*}{$\begin{array}{l}\text { Yes: easy to } \\
\text { pay back }\end{array}$} & \multirow[b]{2}{*}{$\begin{array}{l}\text { Yes: difficult to } \\
\text { pay back }\end{array}$} & \multicolumn{2}{|l|}{ Model 1} & \multicolumn{2}{|l|}{ Model 2} \\
\hline & & & & & $\begin{array}{l}\text { Yes easy to } \\
\text { pay back vs. no } \\
\text { debts }\end{array}$ & $\begin{array}{l}\text { Yes difficult to } \\
\text { pay back vs. no } \\
\text { debts }^{1}\end{array}$ & $\begin{array}{l}\text { Yes easy to } \\
\text { pay back vs. no } \\
\text { debts }\end{array}$ & $\begin{array}{l}\text { Yes difficult to } \\
\text { pay back vs. no } \\
\text { debts }^{1}\end{array}$ \\
\hline $\begin{array}{l}\text { Baseline char- } \\
\text { acteristics }\end{array}$ & $\mathrm{n}$ & $\%$ or M (S.E.) & $\%$ or $\mathrm{M}(\mathrm{S} . \mathrm{E})$. & $\%$ or M (S.E.) & $\begin{array}{l}\text { aRRR }(95 \% \\
\text { CI })\end{array}$ & $\operatorname{aRRR}(95 \% \mathrm{CI})$ & $\begin{array}{l}\text { aRRR }(95 \% \\
\text { CI) }\end{array}$ & $\operatorname{aRRR}(95 \% \mathrm{CI})$ \\
\hline 12-month CMD & 121 & 30.4 & 23.7 & 42.2 & $\begin{array}{c}0.79[0.37, \\
1.68]\end{array}$ & $\begin{array}{c}2.19[1.30 \\
3.68]^{* *}\end{array}$ & $\begin{array}{c}0.79[0.39 \\
1.61]\end{array}$ & $\begin{array}{l}\text { 1.94 [1.13, } \\
3.32]^{*}\end{array}$ \\
\hline Female gender & 277 & 49.9 & 42.5 & 48.0 & $\begin{array}{c}0.60[0.36, \\
1.01]+\end{array}$ & $\begin{array}{l}0.74[0.42, \\
1.31]\end{array}$ & $\begin{array}{l}0.82[0.47, \\
1.42]\end{array}$ & $0.69[0.39,1.20]$ \\
\hline $\begin{array}{l}\text { Age at inter- } \\
\text { view }\end{array}$ & 518 & $40.0(0.68)$ & $37.5(1.06)$ & $41.5(1.46)$ & $\begin{array}{l}0.98[0.95 \\
1.00]^{*}\end{array}$ & $\begin{array}{c}1.01[0.99, \\
1.04]\end{array}$ & $\begin{array}{c}1.00[0.97, \\
1.02]\end{array}$ & $1.01[0.99,1.04]$ \\
\hline \multicolumn{9}{|l|}{ Education } \\
\hline $\begin{array}{l}\text { Primary edu- } \\
\text { cation }\end{array}$ & 33 & 12.3 & 5.7 & 16.7 & & & $\begin{array}{l}0.57[0.14, \\
2.40]\end{array}$ & $1.56[0.59,4.11]$ \\
\hline $\begin{array}{l}\text { Lower sec- } \\
\text { ondary }\end{array}$ & 133 & 24.7 & 20.3 & 31.5 & & & $\begin{array}{l}0.89[0.38 \\
2.12]\end{array}$ & $\begin{array}{l}2.28[1.12 \\
4.67]^{*}\end{array}$ \\
\hline $\begin{array}{l}\text { Higher sec- } \\
\text { ondary }\end{array}$ & 182 & 40.0 & 46.1 & 36.4 & & & $\begin{array}{l}1.21[0.68, \\
2.15]\end{array}$ & $1.59[0.78,3.24]$ \\
\hline $\begin{array}{l}\text { Higher profes- } \\
\text { sional }\end{array}$ & 170 & 23.1 & 27.9 & 15.4 & & & REF & REF \\
\hline $\begin{array}{l}\text { Living without } \\
\text { partner }\end{array}$ & 231 & 50.4 & 58.4 & 50.6 & & & $\begin{array}{l}1.91[1.11, \\
3.28]^{*}\end{array}$ & $0.98[0.55,1.76]$ \\
\hline No paid job & 127 & 24.8 & 9.7 & 32.1 & & & $\begin{array}{c}0.39[0.14 \\
1.12]+\end{array}$ & $1.01[0.51,2.01]$ \\
\hline $\begin{array}{l}\text { Negative life } \\
\text { event }\end{array}$ & 285 & 58.3 & 53.7 & 67.9 & & & $\begin{array}{c}1.05[0.59, \\
1.88]\end{array}$ & $\begin{array}{c}1.67[0.97, \\
2.89]+\end{array}$ \\
\hline $\begin{array}{l}\text { Chronic physi- } \\
\text { cal disorder }\end{array}$ & 229 & 40.0 & 23.2 & 49.2 & & & $\begin{array}{c}0.55[0.28 \\
1.08]+\end{array}$ & $1.16[0.62,2.15]$ \\
\hline $\begin{array}{l}\text { Body mass } \\
\text { index }\end{array}$ & 516 & $25.6(0.30)$ & $24.7(0.51)$ & $26.2(0.64)$ & & & $\begin{array}{l}0.97[0.92 \\
1.03]\end{array}$ & $1.01[0.95,1.07]$ \\
\hline $\begin{array}{l}\text { Current smok- } \\
\text { ing }\end{array}$ & 202 & 43.4 & 43.3 & 47.1 & & & $\begin{array}{l}0.98[0.55, \\
1.74]\end{array}$ & $1.05[0.59,1.87]$ \\
\hline
\end{tabular}

Left part: Characteristics of respondents with debts at baseline, in total and across debts status at follow-up three years later, in weighted column percentages or means $(\mathrm{M})$ and standard errors (S.E.)

Right part: Results of multinomial logistic regression analyses predicting persistence of debts at follow-up (reference group is no debts at followup), in weighted adjusted relative risk ratios (aRRR) with 95\% confidence intervals (95\% CI)

1: The category difficult to pay back includes the categories difficult and very difficult to pay back debts

REF: Reference category

Model 1 and Model 2: All odds ratios are adjusted for all variables in the column concerned

Bold: Significant OR at the 0.05 level, 2 -sided test. $+: P<.10$; *: $P<.05 ; * *: P<.01 ; * * *: P<.001$

Comparable analyses with internalizing (mood/anxiety) and externalizing (substance use) disorders separately are provided in Supplementary Table $4 \mathrm{a}$

significant after controlling for a wide variety of potential confounders.

\section{Discussion of Research Findings}

In the present study, $13.6 \%$ of adults reported being in debt and $6.1 \%$ difficulty in paying back their debts, in line with previous reports in the Netherlands (Den Ridder et al.,
2020). In England, a lower percentage of adults (8.5\%) reported being in debt in 2007 (Meltzer et al., 2012), probably because in that study no upper age limit was applied and older age is associated with lower likelihood of having debts and the data were collected before the "global financial crisis", while most of our data were collected after this economic crisis. Multivariate analyses showed that increasing levels of difficulty in repaying debts increased 
the risk of onset of CMD at follow-up. Conversely, baseline CMD did not increase the risk of onset of debts at follow-up. This means that we found more support for the social causation hypothesis (i.e. debts causing CMDs), than for the social selection hypothesis (CMDs inducing debts). Several factors could explain a link between debts and mental health, including behaviour such as poor sleep, smoking and other health-related behaviours (Hojman et al., 2016; Sweet et al., 2013), psychological factors such as stress, worries, and feelings of personal failure and reduced control over finances (Drentea \& Reynolds, 2012; Richardson et al., 2013; Sweet, 2018), social factors including stigma surrounding debts and mental illness and biological sequalae such as weakened immune system and increased blood pressure (Boen \& Yang, 2016; Sweet et al., 2013). We are unaware of studies that investigated the bidirectional link between debts and mental health in a population sample. Future studies may validate our findings and zoom into potential mechanisms and mediators for the associations between debts and CMDs and develop interventions. One example is evidence that financial resources allow individuals to reduce the impact of unpredicted everyday hassles on negative affect (Jachimowicz et al., 2019), another that showed how reductions in healthcare-related debts improved mental health (Baicker et al., 2018).

The present findings suggest that the association between debts and CMD seems to be driven by the experience of having difficulties in repaying debts. This is in line with a previous review that concluded that financial concern appeared to mediate all of the negative impacts of the amount of debts on health (Turunen \& Hiilamo, 2014), a study that found that the association between debt and mental health is explained by debt stress (Drentea \& Reynolds, 2012), and a study that found that especially non-mortgage debt-primarily consumer credit- or late mortgage payments-and less secured debt (secured by collateral) is associated with depressive symptoms (Hojman et al., 2016).

In the Netherlands, general practitioners (GPs) most often constitute the first point of medical contact and act as gatekeepers to the rest of the health-care system, including mental health care. This implies that GPs more often treat minor mental health problems and specialised mental health services usually CMD. Previous research showed that debts and mental health problems frequently coincide (e.g. Gunasinghe et al., 2018; Richardson et al., 2013). The present study contributes to the literature by showing that increasing levels of difficulty in repaying debts among those with minor mental health problems at baseline increased the risk of onset of CMD at 3-year follow-up. This entails that GPs should monitor patients' debts and mental health status to be able to timely refer the patients who develop a CMD to the appropriate mental health services and to treat those who could benefit from less specialised help. GPs are also suitable care providers in discussing the role debts could play in patients' mental and physical health.

Among respondents with a 12-month CMD, 30\% had debts and $17.9 \%$ experienced difficulty in paying off their debts. Previous research found a somewhat lower percentage of debtors among adults with indication for CMD (23\%); probably because that study was performed before the 2008 financial crisis (Jenkins et al., 2008). These findings show that most people with CMD do not have problematic debts. In line with prior research (Gunasinghe et al., 2018; Rahman et al., 2012), our longitudinal analyses revealed that increasing levels of difficulty in repaying debts among those with a 12-month CMD at baseline predicted persistence of CMD at 3-year follow-up. This suggests that health professionals should routinely enquire about patients' debts, address the potential risk of debts-related stress in patients' mental and physical health and refer those with financial problems to services for debt counselling. Despite the fact that debt counseling is not a main task of mental health professionals, there are recommended actions a psychiatrist could take, including discussing debts and budgeting, providing strategies to cope with pressure from creditors and anxiety, shame and stigma, to face fears, and assess mental capacity to make financial decisions, raise awareness of personal strengths and weaknesses (e.g., impulse control), and discuss personal goal setting (e.g., daily routines and excercise), which may all help reduce debts and related stress.

The present study found that debts are often long-term. Of the respondents with debts at baseline, $53.7 \%$ again reported debts at three-years follow-up and $28.5 \%$ reported that they were (very) difficult to pay off. Furthermore, CMD among those with debts at baseline increased the likelihood of debts becoming (very) difficult to pay off at follow-up. This implies that debt counsellors should pay attention to clients' mental health and refer those with mental health problems to the appropriate services.

The present study used data collected in 2012-2015, a period in which the economy had not yet recovered from the financial crisis of 2008 (in terms of Gross Domestic Product, GDP, per capita, see www.cbs.nl). Previous studies showed that respondents' assessment of their debts is not only influenced by the current constellation of income, debt service and, possibly, the potential subsistence level. Expectations of their personal economic situation and several non-financial factors affect their debt perception as well (Gathergood, 2012; Keese, 2012; Turunen \& Hiilamo, 2014). This means that future studies in profitable and unprofitable time periods are needed to replicate the present findings.

The Coronavirus pandemic will deepen and extend the existing health inequalities (Fisher \& Bubola, 2020; Jeronimus, 2020). It is expected that the current pandemic will hit the economy of Western countries harder than the 2008 
financial crisis, and most Western industries will recover slower this time than they did after the financial crash. The consequences of the upcoming economic crisis and financial hardship as a result of the Coronavirus may have a serious impact on the risk of CMD.

\section{Strengths and Limitations}

This population study contributes to the literature with an assessment of the bidirectional association between debts and CMD in the general population. Major strengths were the nationally representative and prospective data over a 3-year period and a standardized diagnostic instrument to assess CMD. However, some limitations have to be mentioned.

First, although the sample was representative of the Dutch population on most parameters, people with an insufficient mastery of Dutch, those with no permanent residential address and the institutionalized were underrepresented. It is plausible that those with severe CMD and debts also were underrepresented in the sample. Hence, our findings cannot be generalized to these groups, such as patients with severe mental disorders like schizophrenia or obsessive compulsive disorder.

Second, there is no uniform definition for indebtedness (Richardson et al., 2013; Turunen \& Hillamo, 2014). In large population-based studies, it is seldom possible to assess overall solvency, as this would have required detailed assessment of assets and liabilities, which is very time consuming and burdensome for respondents (Meltzer et al., 2012). In many cases, respondents are merely asked whether they can make ends meet, are in arrears or experience difficulties in repaying debts (e.g. Bridges \& Disney, 2010; Drentea \& Reynolds, 2012; Hintikka et al., 1998; Meltzer et al., 2012; Zurlo et al., 2014). These subjective assessments, which are not necessarily the same as objective assessments (Bridges \& Disney, 2010; Dackehag et al., 2018; Keese, 2012), are then used as proxies for actual indebtedness.

Third, although our definition of debts in general resembled that used in previous population-based studies (Gunasinghe et al., 2018; Jenkins et al., 2008; Meltzer et al., 2011), we could not differentiate between subjects experiencing acute repayment difficulties and those with long-term debts. This means that we cannot assess whether findings would be different if we took duration of debts into account.

Fourth, shame may have led to underreporting of debts and repayment difficulties (Jenkins et al., 2008). This would probably have weakened the association found between debts and CMD. Besides, respondents' perception of their debts is not likely affected by a more negative state of mind during the interview, a phenomenon re-appraised by Brewin et al. (1993), in the sub-cohorts predicting onset of CMD and onset of debts. That is because those with a 12-month
CMD or debts at baseline were excluded from the analyses predicting onset of CMD or debts respectively at follow-up. However, this bias could have occurred in the other subcohorts predicting persistence of CMD and persistence of debts, but it is difficult to gauge how this might have influenced the results of our study.

Fifth, severity of CMD could not be considered in the analyses because the numbers of adults with much difficulty to pay back debts and severe CMD were too low to perform meaningful analyses.

Sixth, there is the possibility that any bidirectional association between debts and CMDs could be due to nonobserved sources of confounding. In NEMESIS-2, income was not assessed at baseline (i.e. $\mathrm{T}_{1}$ ). This means that its potential as risk indicator could not be studied. Previous research showed that the relationship between low income and (mental) health is largely mediated by debts (Arber et al., 2014; Fitch et al., 2011; Jenkins et al., 2008), that debts more strongly predicted mental health than any other socioeconomic status (SES) indicator (Drentea \& Reynolds, 2012) and that higher debt-to-asset ratio increased risk of depressive symptoms in both low and high income groups (Zimmerman \& Katon, 2005). Furthermore, in our fully adjusted models the association between debts and CMDs remained robust despite adjustment for several variables that are known to be associated with income, like education, job status, chronic physical disorder, BMI and current smoking status. This implies that if we would have been able to adjust for income, we would have found only slightly weaker associations and might have over-adjusted our findings.

\section{Conclusions}

Our findings suggest that interventions to reduce debts may help prevent onset of CMD in adults, and may contribute to better outcomes in those with an existing CMD. Further research should evaluate if interventions based on debt counselling lead not only to significant reductions of debt burden and debt persistence but also to meaningful improvements in mental health.

Supplementary Information The online version contains supplementary material available at https://doi.org/10.1007/s10488-021-01131-9.

Authors contributions All authors except the 5th and the 6th authors are part of the NEMESIS-2 research team. The 1st and last authors obtained funding for the NEMESIS-2 study and for studying this particular research topic. All authors contributed to the conception, design and interpretation of analysis for this manuscript. The 1st author undertook the analyses for this manuscript and wrote the first draft of the manuscript. All authors discussed the results and implications and commented on the manuscript at all stages. All authors contributed extensively to and have approved the final manuscript. 
Funding NEMESIS-2 is conducted by the Netherlands Institute of Mental Health and Addiction (Trimbos Institute) in Utrecht. Financial support has been received from the Ministry of Health, Welfare and Sport, with supplementary support from the Netherlands Organization for Health Research and Development (ZonMw) and the Genetic Risk and Outcome of Psychosis (GROUP) investigators. The funding sources had no further role in study design; in the collection, analysis and interpretation of data; in the writing of the report; or in the decision to submit the paper for publication.

Data Availability The data on which this manuscript is based are not publicly available. However, data from NEMESIS-2 are available upon request. The Dutch ministry of health financed the data and the agreement is that these data can be used freely under certain restrictions and always under supervision of the Principal Investigator (PI) of the study. Thus, some access restrictions do apply to the data. The PI of the study is first author of this paper and can at all times be contacted to request data. At any time, researchers can contact the PI of NEMESIS-2 and submit a research plan, describing its background, research questions, variables to be used in the analyses, and an outline of the analyses. If a request for data sharing is approved, a written agreement will be signed stating that the data will only be used for addressing the agreed research questions described and not for other purposes.

\section{Declarations}

Conflict of interest The authors declare that they have no competing interests.

Ethical Approval The study was approved by a medical ethics committee (the Medical Ethics Review Committee for Institutions on Mental Health Care, METIGG).

Informed Consent After having been informed about the study aims, respondents provided written informed consent at each wave.

\section{References}

Arber, S., Fenn, K., \& Meadows, R. (2014). Subjective financial wellbeing, income and health inequalities in mid and later life in Britain. Social Science \& Medicine, 100, 12-20.

Baicker, K., Allen, H. L., Wright, B. J., Traubman, S. L., \& Finkelstein, A. N. (2018). The effect of medicaid on management of depression: Evidence from the Oregon Health Insurance Experiment. The Milbank Quarterly, 96, 29-56. https://doi.org/10.1111/14680009.12311.

Black Report. (1980). https://www.sochealth.co.uk/national-healthservice/public-health-and-wellbeing/poverty-and-inequality/ the-black-report-1980/

Boen, C., \& Yang, Y. C. (2016). The physiological impacts of wealth shocks in late life: Evidence from the Great Recession. Social Science \& Medicine, 150, 221-230.

Bosman, R. C., Ten Have, M., De Graaf, R., Muntingh, A. D. T., Van Balkom, A. J. L. M., \& Batelaan, N. M. (2019). Prevalence and course of subthreshold anxiety disorder in the general population; a three-year follow-up study. Journal of Affective Disorders, 247, 105-113.

Brewin, C. R., Andrews, B., \& Gotlib, I. H. (1993). Psychopathology and early experience: A reappraisal of retrospective reports. Psychological Bulletin, 113, 82-98.

Bridges, S., \& Disney, R. (2010). Debt and depression. Journal of Health Economics, 29, 388-403.
Brugha, T., Bebbington, P., Tennant, C., \& Hurry, J. (1985). The list of threatening experiences: A subset of 12 life event categories with considerable long-term contextual threat. Psychological Medicine, $15,189-194$.

Cbs.nl About The Financial Crisis. (2008). https://www.cbs.nl/nl-nl/ nieuws/2018/37/nederland-tien-jaar-na-de-val-van-lehman-broth ers

Dackehag, M., Ellegard, L.-M., Gerdtham, U.-G., \& Nilsson, T. (2018). Debt and mental health: New insights about the relationship and the importance of the measure of mental health. The European Journal of Public Health, 29, 488-493.

De Graaf, R., Ten Have, M., \& Van Dorsselaer, S. (2010). The Netherlands Mental Health Survey and Incidence Study-2 (NEMESIS-2): Design and methods. International Journal of Methods in Psychiatric Research, 19, 125-141.

De Graaf, R., Van Dorsselaer, S., Tuithof, M., \& Ten Have, M. (2015). Sociodemographic and psychiatric predictors of attrition in the third wave of the Netherlands Mental Health Survey and Incidence Study-2 (NEMESIS-2). Trimbos-instituut.

Den Ridder, J., Josten, E., Boelhouwer, J., \& Van Campen, C. (2020). De sociale staat van Nederland 2020. Den Haag.

Drentea, P., \& Reynolds, J. R. (2012). Neither a borrower nor a lender be: The relative importance of debt and SES for mental health among older adults. Journal of Aging and Health, 24, 673-695.

Dubois, H., Fóti, K., Kable, E. \& Anderson, R. (2020). Addressing household over-indebtedness. Eurofond: Publications Office of the European Union, Luxembourg. https://www.doi.org/https:// doi.org/10.2806/25005

Fisher, M. \& Bubola, E. (March, 15, 2020). As Coronavirus Deepens Inequality, Inequality Worsens Its Spread. The New York Times, https://www.nytimes.com/2020/03/15/world/europe/coronavirusinequality.html

Fitch, C., Hamilton, S., Bassett, P., \& Davey, R. (2011). The relationship between personal debt and mental health: A systematic review. Mental Health Review Journal, 16, 153-166.

Gathergood, J. (2012). Debt and depression: Causal links and social norm effects. The Economic Journal. https://doi.org/10.1111/j. 1468-0297.2012.02519.x.

Gunasinghe, C., Gazard, B., Aschan, L., MacCrimmon, S., Hotopf, M., \& Hatch, S. L. (2018). Debt, common mental disorders and mental health service use. Journal of Mental Health, 27, 520-528.

Haro, J. M., Arbabzadeh-Bouchez, S., Brugha, T. S., De Girolamo, G., Guyer, M. E., Jin, R., Lepine, J. P., Mazzi, F., Reneses, B., Vilagut, G., Sampson, N. A., \& Kessler, R. C. (2006). Concordance of the composite international diagnostic interview version 3.0 (CIDI 3.0) with standardized clinical assessments in the WHO World Mental Health Surveys. International Journal of Methods in Psychiatric Research, 15, 167-180.

Hintikka, J., Kontula, O., Saarinen, P., Tanskanen, A., Koskela, K., \& Viinamaki, H. (1998). Debt and suicidal behaviour in the Finnish general population. Acta Psychiatria Scandanavia, 98, 493-496.

Hojman, D. A., Miranda, A., \& Ruiz-Tagle, J. (2016). Debt trajectories and mental health. Social Science \& Medicine, 167, 54-62.

Jachimowicz, J., Frey, E. L., Matz, S. C., Jeronimus, B. F. \& Galinsky, A. D. (2019). Financial scarcity is linked to higher negative affect variability and reduced well-being. Preprint. https://doi.org/10. 31234/osf.io/m9k2f.

Jenkins, R., Bhugra, D., Bebbington, P., Brugha, T., Farrell, M., Coid, J., Fryers, T., Weich, S., Singleton, N., \& Meltzer, H. (2008). Debt, income and mental disorder in the general population. Psychological Medicine, 38, 1485-1493.

Jeronimus, B. F. (2020). Personality and the coronavirus Covid-19 pandemic. University of Groningen Press. https://doi.org/10.21827/ 5ed9ebc01d65f. 
Keese, M. (2012). Who feels constrained by high debt burdens? Subjective vs. objective measures of household debt. Journal of Economic Psychology, 33, 125-141.

Kessler, R. C., \& Üstün, T. B. (2004). The World Mental Health (WMH) Survey Initiative Version of the World Health Organization (WHO) Composite International Diagnostic Interview (CIDI). International Journal of Methods in Psychiatric Research, 13, 93-121.

Matthews, K. A., \& Gallo, L. C. (2011). Psychological perspectives on pathways linking socioeconomic status and physical health. Annual Review of Psychology, 62, 501-530.

Meltzer, H., Bebbington, P., Brugha, T., Farrell, M., \& Jenkins, R. (2012). The relationship between personal debt and specific common mental disorders. European Journal of Public Health, 23, 108-113.

Meltzer, H., Bebbington, P., Brugha, T., Jenkins, R., McManus, S., \& Dennis, M. S. (2011). Personal debt and suicidal ideation. Psychological Medicine, 41, 771-778.

Piketty, T. (2014). Capital in the twenty-first century. . Harvard University Press.

Rahman, A., Sikander, S., Malik, A., Ahmed, I., Tomenson, B., \& Creed, F. (2012). Effective treatment of perinatal depression for women in debt and lacking financial empowerment in a lowincome country. The British Journal of Psychiatry, 201, 451-457.

Richardson, T., Elliott, P., \& Roberts, R. (2013). The relationship between personal unsecured debt and mental and physical health: A systematic review and meta-analysis. Clinical Psychology Review, 33, 1148-1162.

Skinner, C. J., Holt, D., \& Smith, T. M. F. (1989). Analysis of complex surveys. . Wiley.
Sweet, E. (2018). "Like you failed at life": debt, health and neoliberal subjectivity. Social Science \& Medicine, 212, 86-93.

Sweet, E., Nandi, A., Adam, E., \& McDade, T. W. (2013). The high price of debt: household financial debt and its impact on mental and physical health. Social Science \& Medicine, 91, 94-100.

Ten Have, M., Nuyen, J., Beekman, A., \& De Graaf, R. (2013). Common mental disorder severity and its association with treatment contact and treatment intensity for mental health problems. Psychological Medicine, 43, 2203-2215.

Ten Have, M., De Graaf, R., Van Dorsselaer, S., Tuithof, M., Kleinjan, M., \& Penninx, B. W. J. H. (2018). Recurrence and chronicity of major depressive disorder and their risk indicators in a population cohort. Acta Psychiatrica Scandinavica, 137, 503-515.

Turunen, E., \& Hiilamo, H. (2014). Health effects of indebtedness: a systematic review. BMC Public Health, 14, 489.

Vollebergh, W. A. M., Iedema, J., Bijl, R. V., De Graaf, R., Smit, F., \& Ormel, J. (2001). The structure and stability of common mental disorders: The NEMESIS-study. Archives of General Psychiatry, 58, 597-603.

Zimmerman, F. J., \& Katon, W. (2005). Socioeconomic status, depression disparities, and financial strain: What lies behind the incomedepression relationship? Health Economics, 14, 1197-1215.

Zurlo, K. A., Kim, H., \& Yoon, W. A. (2014). Unsecured consumer debt and mental health outcomes in middle-aged and older Americans. Journals of Gerontology, Series B: Psychological Sciences and Social Sciences, 69, 461-469.

Publisher's Note Springer Nature remains neutral with regard to jurisdictional claims in published maps and institutional affiliations. 